\title{
Analysis of the Effect of Distributed Generation on Loss Reduction in Electrical Distribution Network
}

Ganiyu Adedayo Ajenikoko, Adebayo Wasiu Eboda, Abass Balogun, Adenle Musibau Shittu, Yusuf Mukhtar Department of Electronic and Electrical Engineering, Ladoke Akintola University of Technology, P.M.B, 4000,

Ogbomoso, Nigeria

\begin{abstract}
Distribution network is said to be the most visual part of the electric production and the most observed by the utilities for investment, maintenance and operation. The system have been operated under stressed conditions due to limited structure and increasing day to day requirement of power consumption, which have a significant economic and social impact on the system. Due to the system high resistance to impendence ratio, large amount of power loss occur in the network. This loss is the most severity factors affecting the power quality delivered to the end users and depend on power network expansion and load complexity. Among the support methods available for power loss minimization in distribution network, strategic allocation of Distributed Generation (DG) in distribution system is widely considered a viable option. DGs are electrical sources connected to the power network located to consumer's side but very small when compared with the centralized power plant. They can be in form of wind, mini-hydro, photovoltaic and fuel-based system such as fuel cells and micro-turbines. Therefore, in this study, different approaches for power loss minimization in electrical distribution system with the incorporation of DG by various researchers were reviewed. These approaches have become powerful tools to overcome the problem of power loss minimization in distribution system.
\end{abstract}

Keywords: Distribution System, Power Loss. Distributed Generation, Power Consumption, Photovoltaic System, Centralized Power Plant.

DOI: $10.7176 /$ JETP/11-6-02

Publication date: November $30^{\text {th }} 2021$

\section{I.Introduction}

The performance of distribution system is the ultimate issues bothering the power distribution system operator. This is essential in order to fulfill load demands, which increase tremendously. The process in enhancing the efficiency of the distribution network is beset by high real power losses especially in the conventional radial distribution system [5]. This has brought a difficult task to power operators in sustaining a reliable network economically. Distribution system loss reductions constitute a significant part of the total electrical power deterioration. However, despite this identified problem, the demand for power is constantly increasing on daily basis. Therefore, in order to gain a better performance of electricity supply service, there is the need to minimize power loss in distribution system [1-4].

Electric utilities operators are concerned with maintaining distribution system losses within the specified limit due to increase in population, unscheduled loading and other economic and ecological restrictions. Hence, the main achievement in power system operations is the power loss minimization in distribution system. Distribution power losses are chiefly affected by types of connected loads, voltage and current conditions in the system, number and characteristics of electrical device. Therefore, the quest to appreciably reduce the power loss is the emergent desire of power system engineers [6], [9], [12].

Distributed Generation (DG) is an electrical resources connected directly to the distributed network. The DGs include; turbines, Photo-voltaic (PV), fuel cells, and storage devices. Hence; integration of DG into the distribution network results in the highest loss reduction, improved voltage profile, improving system reliability and security. Thus, The DG has become an efficient and clean alternative for the traditional electric energy sources and recent technologies are making DGs economically feasible [8], [17].

DG is more economical than running a power line to rural area because it provides back-up power during outages for facilities requiring uninterrupted service, provide higher power quality for electronic equipment and aids network stability when employed using fast response equipment for a secured distribution system [10-11], [42].

\section{a. Power Distribution Network}

Distribution network is the last stage in the supplying of electric power in order to provide power to individual consumer premises [13]. Distribution substations lower the transmission voltage to medium voltage with the use of transformers. Distribution lines connect the medium voltage to distribution transformers located near the individual customer's premises while the transformers adjust the voltage to the household utilization voltage through secondary distribution lines [17], [27].

In practice, power distribution system can be radial or ring with a single or multiple alternate sources. A radial distribution system is a separate feeder which radiates from a lone sub-station but feed the distributor at other end. 
The network is a distribution network where power is been transferred from the main branch to the sub-branch and splits out from the sub-branches to the load as shown in Figure 1 [14]. The radial structure indicates no loops in the networks and each bus is connected to the source through one path [16] [19].

Generally, the cost of the construction of the ring main system is higher compared with the radial system. Also, more switches and conductors are essential in ring main system construction. Thus, the system is not ideal for low voltage level and also have high construction cost. Thus, due to these factors the radial system is widely used in distribution network [15], [18], [20].

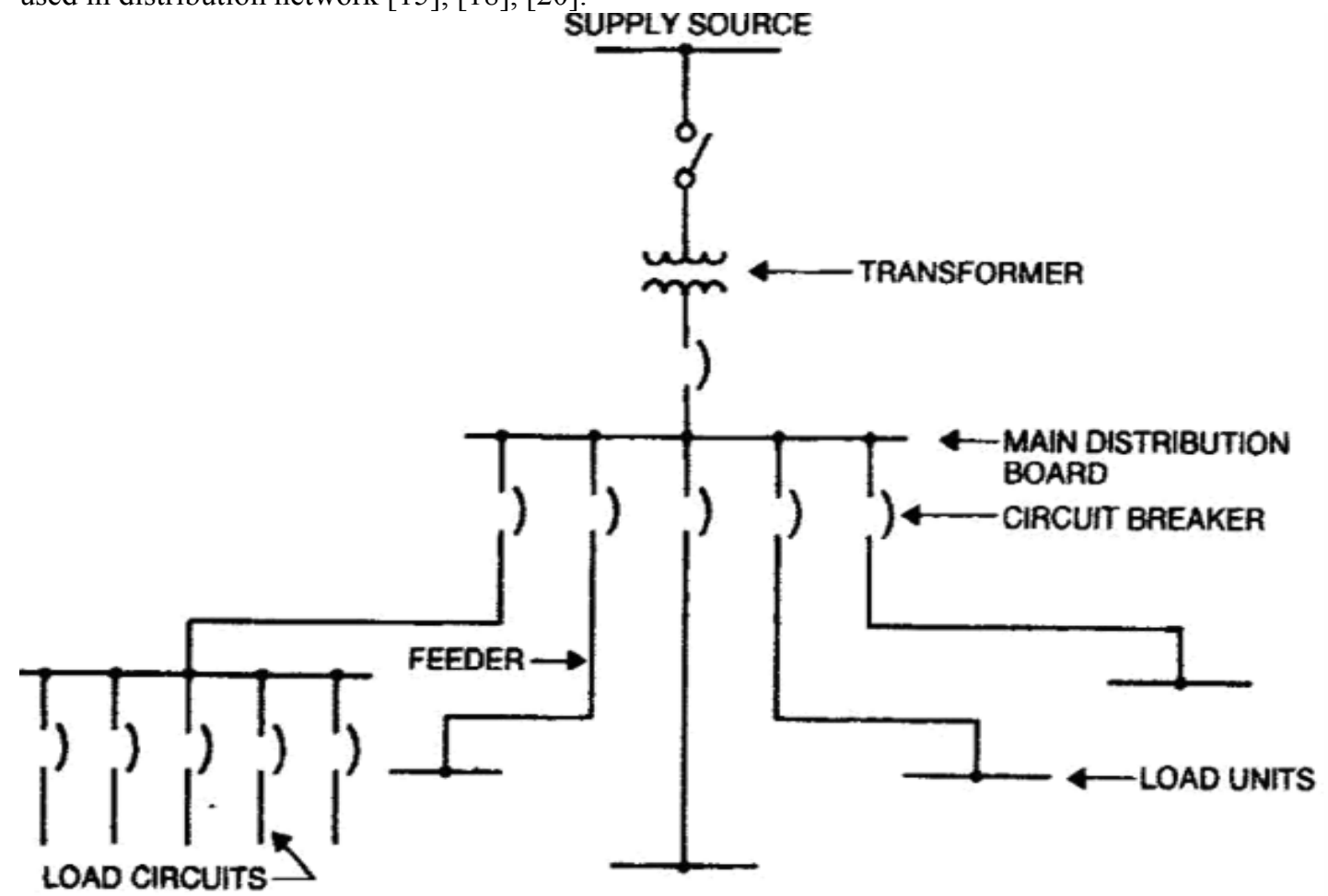

Figure 1: A Radial Distribution System

\section{b. Losses in Distribution System}

Distribution system power losses are the major problem in power sector and occur as a result of distributing electric energy end users. This may lead to performance of distribution system to become inefficient [11]. Power losses in distribution system are either real loss or reactive loss. The real power loss occurs due to the line resistance while reactive power loss is due to the reactive elements. The real power loss reduction draws more attention due to its significant effect on reducing the efficiency of distribution power to the end users. However, reactive power needs to be maintained to ensure transfer of real power at sufficient voltage level to customers. These losses have turn into the most concerned issue for power system engineers because it minimizes the capability of electric energy transfer to the consumer [21], [25].

Factors that influence power losses are: failure in maintaining the voltage profile across networks due to the flow of circulating current, power factor at unity which increases in current and resultant in the real power losses and voltage regulation which reduces both maximum demand and energy losses [10],[30]. Abbagane et al. (2010) analyzed that $70 \%$ of power losses occurred in the distribution system [1]. Therefore, improving the capability of electric power delivery and this has forced the power engineers to be able to reduce the power loss in the distribution network. In this case, changing environment of electric network design and operation has necessitated the need to consider active distribution network with DG incorporation. The inclusion of DR in distribution network improve the voltage profile and reduce power loss in distribution network.[24], [26].

\section{c. Distributed Generation}

Nowadays, one of the alternative solutions to traditional power system operation in order to meet electric energy demands is Distributed Generation (DG). DG is one of the current techniques in decentralized power systems to supplement the increase in power demand. The DG also called decentralized generation; dispersed generation or embedded generation is considered as source of electrical energy connected directly to the distribution network [23]. According to Kansal et al. (2011), DG is defined as a small generating units of $30 \mathrm{MW}$ or less, sited near customer sites to meet provide to support the economic operation of the distribution network [21].

DG impact on distribution system has attracted much attention due to its capacity to correct the flaws caused by its improper installation at feeders, such as those in system losses, reduction in power quality and improvement 
of voltage at the feeders [3-4], [28], [42]. DG includes renewable; wind, solar, and biomass, and nonrenewable energies; micro-turbines, gas turbines and fuel cells. However, the environmental benefits of renewable DG energies outweigh that of non-renewable DG energies [28], [42].

In addition, installing DG on power network has influences on the network parameters. These impacts can be positive or negative [27], [29]. The formal includes increasing the power quality, improving the voltage profile and deferring the necessity of improving the capacity of substations [4]. While the later includes injection of voltage with harmonics and protection coordination. Therefore, there is the need for new network planning that can guarantee the changes in the distribution- load configuration for technical constraints and penetration levels, in such a way that the benefit is maximized. These limitations must be resolved before introducing DG as an alternative option [31], [36]

The DG technologies which are available at present are depicted in Table 1. There are other technologies besides the listed ones [6], [26], [28], [32-33].

In addition, interconnection of DG into distribution system offers major benefits which can be classified as follows [34-35], [37]:

i. Technical Benefits: DG can provide benefits such as; voltage magnitude improvement, minimization of line losses, power quality adjustment and enhancement in system reliability and security.

ii. Economic Benefits: These include; belated the facilities investments for upgrading, operational and maintenance costs minimization of some DG technologies, enhanced productivity, reduced health care costs, reduced fuel costs, associated costs and lower operating costs.

iii. Environmental Benefits: DG offer an environmentally friendly source of electrical power by reduced pollutants and encourage the use of renewable energy based generation.

More so, the effect of DG in the operation of power network nowadays has become eminent. DGs are reduced characterized as electric sources joined precisely to the distribution network or on the customer side. Higher penetration levels of DG modified the conventional power flows as the power injected at any point on the feeder with DG units [38-39].

Table 1: Options for Small Scale DG

\begin{tabular}{|c|c|c|c|}
\hline Type & Size Range $(\mathrm{kW})$ & $\begin{array}{l}\text { Electrical } \\
\text { Efficiency }(\%)\end{array}$ & Applications \\
\hline Biomass energy & $5-10000$ & $40-50$ & Co-generation and grid Support \\
\hline Fuel Cells & $1-1000$ & $41-66$ & Co-generation and grid support \\
\hline Micro Turbines & $30-5000$ & $20-35$ & $\begin{array}{l}\text { Stand-by power, reliability, power quality and } \\
\text { cogeneration }\end{array}$ \\
\hline Photovoltaic Arrays & $1-100$ & $5-15$ & Base load, peak shaving \\
\hline $\begin{array}{l}\text { Reciprocating } \\
\text { Engines }\end{array}$ & $5-7000$ & $25-45$ & $\begin{array}{l}\text { Backup power, base load, grid support and } \\
\text { peak Shaving }\end{array}$ \\
\hline Stirling Engines & $1-25$ & $12-20$ & Vehicles, Refrigeration Aircraft, Space \\
\hline Wind systems & Several kW-5000 & $20-40$ & Remote power, grid Support \\
\hline
\end{tabular}

\section{Approaches for Power Distribution Loss Minimization with DG}

Deependra et al (2007) [10] used Genetic Algorithm (GA) for optimal integration of Distributed Generation (DG) at diverse loading conditions in electric power system in order to reduced system loss. The strategy was implemented on IEEE 16, 37 and 75-bus power systems. The paper concluded that during light load conditions, the optimal placements of DG difference at minimum loss but very close during heavy load periods.

Sedighizadeh and Rezazadeh (2008) [37] used Genetic Algorithm (GA) for power loss reduction as well as for voltage profile improvement of electric distribution network with optimal integration of Distribution Generation (DG). The algorithm was implemented on Tehran electricity distribution system and simulated using both MATLAB and ETAP software respectively. The simulation result showed an improvement in system voltage profile and loss reduction indices.

Subrahmanyam and Radhakrishna (2009) [40] used Voltage Index (VI) analysis to investigated the best placement and sizing of Distributed Generation (DG) in three-phase Unbalanced Radial Distribution System (URDS) aimed at power loss minimization and system voltage profile improvement. The results of simulation were tested on IEEE 25 and 37- bus unbalanced radial distribution system.

Abbagana et al. (2010) [1] used Differential Evolution (DE) for optimal location and size of Distributed Generation (DG) in order to reduce the power losses and improve the voltage magnitude of distribution network. The algorithm was implemented on IEEE 33 bus radial distribution network and simulation was done using MATPOWER and MATLAB software. The results revealed that the system loss was reduced to the barest minimum with the installation of DG. The study concluded that proper placement and sizing of DG in power system have a significant impact on system loss reduction as well as voltage profile improvement.

Manjunatha and Vittal (2010) [25] employed a heuristic technique; Network Performance Enhancement 
Index (NPEI) for provision of Distributed Generation (DG) source in a distribution network. The developed approach was applied and tested on IEEE 33 and 90-bus power system respectively. The results obtained showed that the technique gave better and economical solution for system improvement.

Amanifar and Hamedani (2011) [6] presented a heuristic optimization technique; Particle Swarm Optimization (PSO) and sensitivity analysis for Distributed Generation (DG) placement aimed at loss reduction, Third Harmonic Distortion (THD) reduction and voltage profile improvement in distribution network. The approach was tested on IEEE 15-bus radial distribution network. The results showed the best position of DG with minimum economic cost. This indicated that PSO have effectiveness to search optimum point and size of DGs on power system.

Kansal et al. (2011) [21] employed Particle Swarm Optimization (PSO) to find the optimal location and sizing of Distributed Generation (DG) in the radial distribution system for active power losses minimization and enhancement of voltage magnitude. The technique was implemented on IEEE 33-bus power system and the obtained results were compared with the exhaustive load flows technique. The results revealed that the optimal placement of DG by PSO improved the system voltage magnitude as well as appreciably reduced the system real power loss.

Mohammad and Akbari (2011) [29] used Particle Swarm Optimization (PSO) for optimal location of Distributed Generators (DG) in the radial distribution systems to reduce the real power losses and to improve the reliability of the power system. The algorithm was implemented on a IEEE 12 bus power system and simulated in a MATLAB environment. The results presented were compared with different approaches and the results revealed that the algorithm out-performed the other methods in terms of computational efficiency.

Satish et al. (2011) [36] employed Particle Swarm Optimization (PSO) to find the optimal placement and sitting of Distributed Generation (DG) in distribution networks in order to reduce the real power losses as well as enhanced the system voltage profile. The technique was implemented on IEEE 33-bus power system and the obtained results were compared with the load flows technique. The result showed that by taking the voltage limits of the system into consideration, the optimal placement of DG by PSO technique minimized the real power loss.

Chandrasekhar et al. (2012) [9] presented Voltage Index (VI) analysis for optimal placement and siting of Distributed Generators (DGs) for system loss minimization and tested on 38-bus distribution systems. Wind and solar systems were modeled as constant power factor and variable reactive power model respectively. The indices of the total system were related with and without considering the DGs limiting busses.

Ghamgeen and Rashed (2012) [12] analyzed optimal location and setting of Thyristor Control Series Compensator (TCSC) for power loss reduction using Differential Evolution (DE) and Genetic Algorithm (GA) by comparing their performances. The simulations were carried out on a IEEE 5-bus and 14-bus power system. The obtained results indicated that DE was easy to use, fast and robust compared to GA.

Hossein and Morteza (2012) [16] presented an optimal sizing and placement of Distributed Generation (DG) considering different load models using Improved Harmony Search (IHS) algorithm. The algorithm was implemented on 69-bus distribution systems. The paper concluded that, the IHS algorithm had good capability for most of the continuous optimization problems. The obtained results showed a better performance compared to other approaches.

Jasrul and Mohd (2012) [18] implemented Iterative Particle Swarm Optimization (IPSO) algorithm for sizing DG units and its performance were related with two other optimization technique; Artificial Immune System (AIS) and Evolutionary Programming (EP). The method was implemented on 69 bus distribution systems with 4 units of DG that operated in PV mode. The results showed that, IPSO gave better results compared to EP and AIS in terms of power loss reduction and voltage profile,

Lieven et al. (2012) [23] investigated the effect of converter connected DG units on harmonic losses in the distribution system. The research introduced numerous indices to quantify the DG benefits. The most important indices were the line reduction and transformer losses, improved system voltage profile, enhanced power quality, reduced environmental impacts and relieved transmission and distribution congestion. The obtained results indicated a decrease in power losses per phase when the DG unit was connected to the most loaded phase.

Mohit et al. (2012) [31] used Ladder Load Flow (LLF) algorithm to investigate the effect of multiple Distributed Generation (DG) distribution system for the minimization of power loss. The method was tested on a 3-phase radial distribution feeder with laterals and sub-lateral generations. An approximation formula was used to minimize the number of required solution.

Slaven et al. (2012) [38] employed Genetic Algorithms (GA) to determine the capacity of Distributed Generation (DG) in power system. The obtained results based on minimal losses showed that GA had a fast convergence towards a set of optimal solutions. Thus, a substantial increase of distributed production in low and medium voltage networks result in decentralizing power systems as well as favoring renewable energy sources to decrease greenhouse effect.

Srinivasa and Nageswara (2012) [39] employed Immune Algorithm (IA) method and Harmony Search Algorithm (HSA for optimal location of multiple Distributed Generator (DG) in distribution network for loss 
reduction. The methods were tested on IEEE 33 and 69-bus radial distribution network. The author concluded that when comparing the results with Immune algorithm method, the results showed that Harmony search algorithm gave the same real power loss and voltage with less distributed generator size than Immune algorithm method.

Syed and Shah (2012) [41] investigated the effect of Distributed Generators (DG) under occurrences of faults on electrical distribution network. The simulations were considered on different types of wind turbines. The results showed how voltage dips were cause by different line faults which affected the network circuit breakers coordination with the inclusion of DG.

Aida and Azah (2013) [2] presented Gravitational Search Algorithm (GSA) for suitable placement of Distribution Generation (DG) in distribution network. The performance of the algorithm was compared with Particle Swarm Optimization (PSO) and Evolutionary Programming (EP). The algorithm was implemented on 69bus distribution network. The obtained results indicated that GSA performance better in terms of the best fitness and convergence rate. It also revealed that the GSA was effective for optimum sitting of DGs in power network.

Behnam (2013) [8] implemented a Particle Swarm Optimization (PSO) and Weighted Coefficient Method (WCM) for optimization of Distributed Generation (DG) in distribution network aimed at network power quality and reliability improvement. The simulation was implemented on IEEE 12-bus power system. Newton-Raphson (NR) algorithm was employed in each island. However, when DGs or load point voltage constraints are not satisfies, the island would be shut down. However, the method used was not guaranteed to be optimal.

Gummadi and Obulesh (2013) [13] employed Sensitivity Analysis (SA) for power loss reduction in distribution feeder in terms of Distributed Generator (DG) size. The technique was verified using MATLAB and the results showed that the inclusion of DG in the distribution network provided an effective solution for power loss reduction as well as improving the voltage profile in the network.

Haruna and Sanusi (2013) [15] employed Ranked Evolutionary Particle Swarm Optimization (REPSO) for allocation of Distributed Generator (DG) in distribution network for improving the voltage profile and network losses reduction. The effectiveness of the algorithm was demonstrated on 69-bus power system. The obtained results showed that installation of DG in the system could improve the system voltage profile and at the same time reduced the network losses.

Julius and Nicodemus (2013) [20] presented Genetic Algorithm Immune Particle Swarm Optimization (GAIPSO) for optimal siting and size a multi-type DG on IEEE 57-bus power system aimed at network losses reduction and voltage magnitude improvement. The obtained results revealed that the network losses reduced to minimum and the voltage magnitude in the network improved from its bus voltage deviation with inclusion DG.

Manafi et al. (2013) [24] employed Particle Swarm Optimization (PSO) and Differential Evolution (DE) algorithms for optimal location of Distributed Generations in distribution network in order to minimize real power losses. Simulation result was implemented on IEEE 33 and 69-bus power systems. It was observed that both PSO and DE techniques gave suitable results.

Engy et al. (2014) [11] presented Combined Heat and Power (CHP) for optimal sizing and siting of Distributed Generators (DG) for distribution cost maximization. The algorithm was simulated in MATLAB environment and implemented on IEEE 37-bus feeder. Obtained results showed the effectiveness of the CHP for optimal selection of DGs size and siting in order to maximize the total cost in the network.

Hamid et al. (2014) [14] presented an algorithm for the optimal quantity and siting of DG and capacitors simultaneously in a distribution network. The models were evaluated on IEEE-33 bus power system. The paper showed that the network simultaneous operated at optimal level with expansion of DG units in the network.

Jegadeesan and keerthana (2014) [19] implemented an Artificial Bee Colony (ABC) for optimal size of DG unit's and proper placement in distribution network to minimize the total network loss. Algorithm was tested on IEEE 15 and 34 bus power systems. Obtained results clearly explained that the optimal placement and siting of DG minimized the network losses.

Kavitha and Muthamil (2014) [22] used Hybrid Genetic Algorithm and Particle Swarm Optimization Search (HGAPSO) for Distributed Generators (DG) placement in distribution network. The analysis was implemented on IEEE 18 bus system. The results of indicated that HGAPSO provided best fitness, high convergence rate and also demonstrated the capability of the technique for average $\left(\mathrm{THD}_{\mathrm{V}}\right)$ and network loss minimization.

Nasser and Gbolamreza (2014) [32] analyzed the optimal placement methods for sizing and location of Distributed Generation (DG) in distribution network. The algorithms were implemented on IEEE 33 bus reconfigured power system and simulated in MATLAB environment with multiple DG units. The results showed that the efficiency of the algorithms used improved the voltage profile and reduced the power losses.

Ramakanth and Vinod (2014) [34] presented an Improved Teaching-Learning Based Optimization (ITLBO) algorithm for optimal DG placement in electrical distribution network. The algorithm was implemented on IEEE33 and 69-bus distribution network and simulated in MATLAB environment. The simulation results revealed the effectiveness of the ITLBO.

Rashmi and Surya (2014) [35] presented Genetic Algorithm (GA) for the optimal siting and sizing of Distributed Generator (DG) in distribution system. The algorithm was simulated in MATLAB environment and 
implemented in a IEEE 16 bus power system. The results verified the analytical approaches.

Attia (2015) [7] used a Backtracking Search Optimization Algorithm (BSOA) for assigning multiple DGs in distribution networks. Loss sensitivity factors and bus voltages were employed based on fuzzy rules to identify the initial DG's placement. The method was validated with different DG sizes and complexities through many radial distribution networks. The results showed that application of BSOA could efficiently generate high-quality solutions for DG placement.

Ajenikoko and Eboda (2015a) [3] analyzed the impact of Dispersed Generation (DG) on optimization of power export using Line Loss Reduction Index (LLRI) based on computer simulation of hourly loads. The simulation was implemented on the selected feeders of Kaduna distribution system. The results showed that with the line application of loss reduction index, the losses were reduced and optimization of power export was achieved when DG are integrating into the distribution network,

Ajenikoko and Eboda (2015b) [4] discussed the impact of embedded generation on network voltage collapse on distribution network using Voltage Stability Index (VSI). Simulation was carried out by reconfiguring the distribution network of Afe Babalola University (ABUAD), Ado-Ekiti. The results showed that after the reconfiguration of the network, the maximum active power, reactive power and voltage connected loads on selected transformer increased respectively.

\section{III.Review Analysis}

In this study, 34 research papers were reviewed with sixteen different approaches used for power loss minimization with incorporation of DG on distribution system for nine (9) years 2007-2015. Each technique tried to mitigate the power loss minimization problem with various objectives and constraints. Some objectives such as cost minimization and voltage magnitude improvement were common in most of them. Most of the reviewed paper focused on implementing the techniques on standard networks while only few researchers applied the techniques to practical network.

Figure 2 shows the relationship between numbers of paper reviewed and reviewed years. From the Figure, 34 papers were reviewed within nine (9) years. One (1) paper each was reviewed for 2007, 2008 and 2009 respectively. Two papers were reviewed in 2010 while four (4) papers were reviewed in 2011. Year 2012 recorded highest number of reviewed papers with nine (9) papers while six (6) papers were reviewed in year 2013. In addition, seven (7) and three (3) papers were reviewed in Years 2014 and 2015 respectively.

Figure 3 indicated the relationship between different approaches for DG implementation on distribution system and number of researchers. It was observed from the Figure that one (1) researcher each employed Backtracking Search Optimization Algorithm (BSOA), Firefly Algorithm (FA), Genetic Algorithm Immune Particle Swarm Optimization (GAIPSO), Hybrid Genetic Algorithm Particle Swarm Optimization Search (HGAPSO), Immune Algorithm and Harmony Search Algorithm (IA-HAS), Improved Harmony Search Algorithm (IHSA), Improved Teaching-Learning Based Optimization (ITLBO), Line Loss Reduction Index (LLRI), Network Performance Enhancement Index (NPEI), Ranked Evolutionary Particle Swarm Optimization (REPSO) and Gravitational Search Algorithm (GSA) for power loss minimization with incorporation of DG. Three researchers employed Deferential Evolution (DE) for power loss minimization while four (4) researchers each employed Genetic Algorithm (GA) and Sensitivity Analysis (SA) approaches respectively. Five researchers employed Voltage Stability Index (VSI) while seven (7) researchers employed Particle Swarm Optimization (PSO).

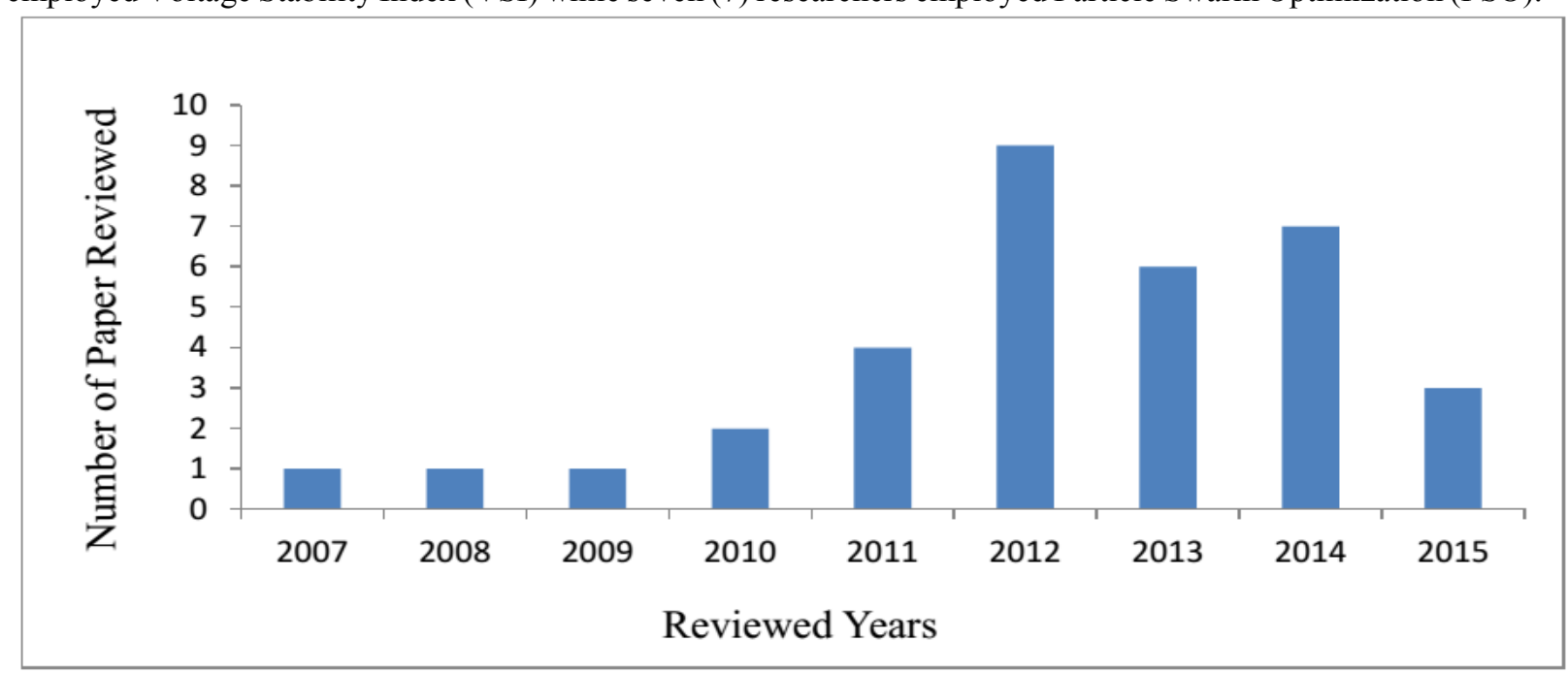

Figure 2: Relationship between numbers of Paper Reviewed and Reviewed Years 


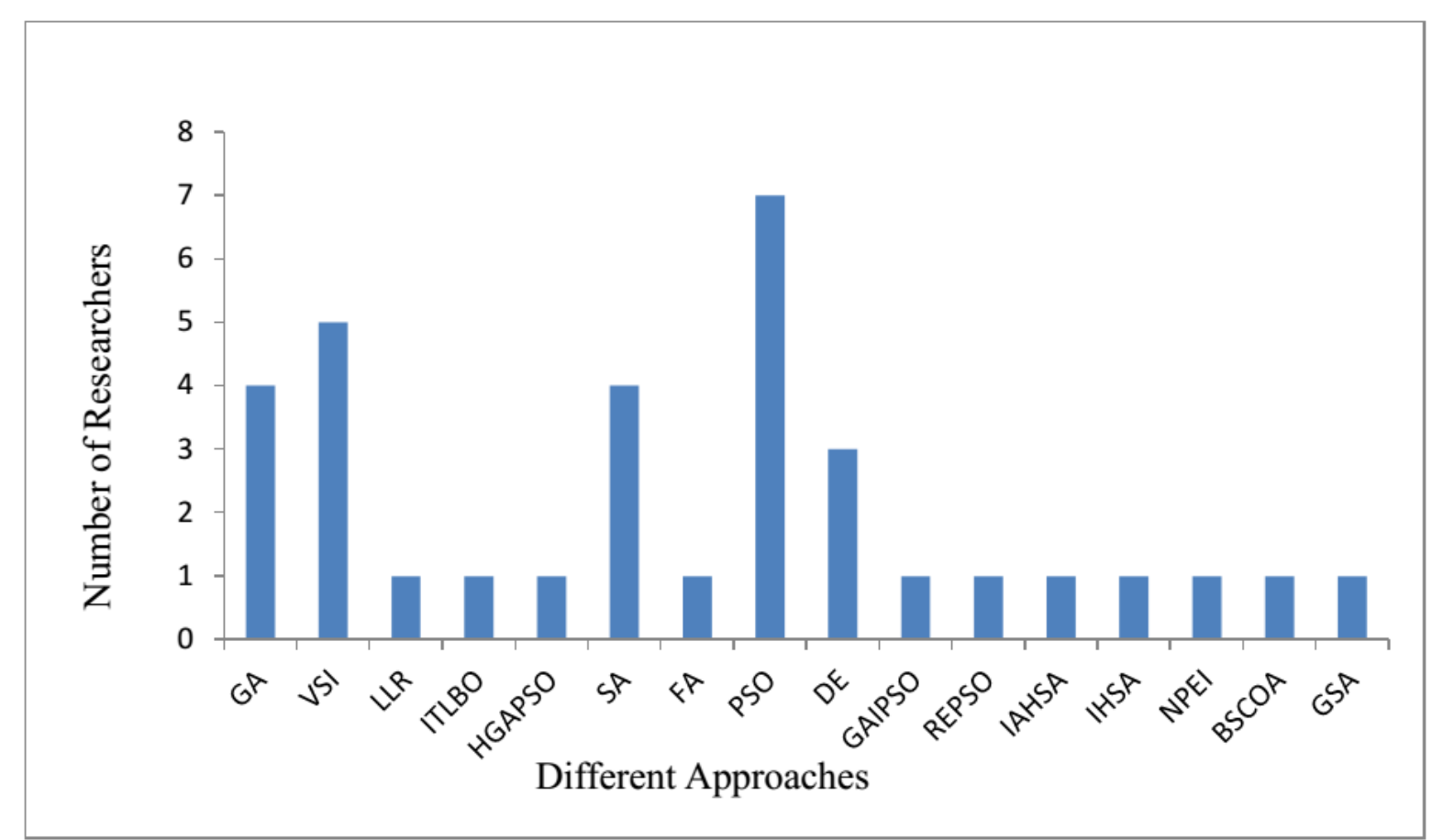

Figure 3: Relationship between different Approaches and Number of Researchers

\section{IV.Conclusion}

A comprehensive analysis of the various techniques employed for power loss minimization in distribution system with integration of Distributed Generation (DG) had been reviewed and presented in this study. The review showed that with incorporation of DG in distribution network, the total power losses along distribution lines are reduced and this enhanced the performance of the distribution system infrastructure. The review also showed that incorporation of DG into the distribution system had technical benefits that complement the distribution system performance through minimization of power losses, thus improving electrical energy delivered to the consumers.

\section{VI.References}

[1] Abbagana, M., Bakare, G. A. and Mustapha, I. (2010). Optimal placement and sizing of a distributed generator in a power distribution system using differential evolution. Proceedings of the 1st International Technology, Education and Environment Conference (c) African Society for Scientific Research, Human Resource Management Academic Research Society: 536-549.

[2] Aida F.A and Azah M. (2013): "Optimal sizing and placement of distributed generation in distribution system considering losses using gravitational search algorithm” Przegląd Elektrotechniczny, http: //www.iiste.org. Vol. 5, No. 3, Pp. 132-136.

[3] Ajenikoko G.A and Eboda A.W (2015a): "Impact of dispersed generation on optimization of power exports" International Journal of Engineering Research and Applications, Vol. 5, No. 5, Pp. 61 - 67.

[4] Ajenikoko G.A and Eboda A.W (2015b): "Impact of embedded generation on power distribution system voltage collapse" European Journal of Computer Science and Information Technology,Vol. 3, No. 4, Pp. 33 -42 .

[5] Ali Kadhem A. (2006): "Load flow method for radial system with distribution generation" A Lecture Note of Technical College, Najaf, Iran. www.google.com. Vol. 2, No. 4, Pp. 1-15.

[6] Amanifar O.M.E and Hamedani G. (2011): "Optimal distributed generation placement and sizing for loss and Thd reduction and voltage profile improvement in distribution system using particle swarm optimization and sensitivity analysis" International Journal on Technical and Physical Problems of Engineering (IJTPE), Vol.3, No.6, Pp. $47-53$.

[7] Attia E. (2015): "Optimal allocation of multi-type distributed generators using backtracking search optimization algorithm" International Journal of Electrical Power and Energy Systems, Vol.64, No. 2, Pp. 1197-1205.

[8] Behnam A. (2013): "Optimum design of DG-based distribution system considering power quality and reliability indices using PSO” Middle-East Journal of Scientific Research, Vol. 18, No. 5, Pp. 829-836.

[9] Chandrasekhar Y, Sydulu M and Sailajakumari M.(2012): "Optimal placement of multi DGs in distribution system with considering the DG bus available limits" Energy and Power, Vol. 2, No. 9, Pp. 18-23. 
[10] Deependra S, Devender S and Verma K.S. (2007): “GA based optimal sizing and placement distributed generation for loss minimization" International Journal of Computer and Electrical Engineering, Vol. 1, No. 3, Pp. $556-561$.

[11] Engy A.M, Mahmoud M.O, Yasser G and Hegazy T. (2014): “Optimal sizing and placement of distributed generators for profit maximization using firefly algorithm” Int'l Conference on Artificial Intelligence, Energy and Manufacturing Engineering, Vol. 4, No. 7, Pp. 6 - 10.

[12] Ghamgeen I and Rashed J. (2012): "Optimal location and parameter setting of TCSC for loss minimization based on differential evolution and genetic algorithm" International Conference on Medical Physics and Biomedical Engineering, Physics Procedia, Vol.33, No. 5, Pp. $1864-1878$.

[13] Gummadi S.R and Obulesh Y.P. (2013): "Voltage profile improvement of distribution system using distributed generating units" International Journal of Electrical and Computer Engineering (IJECE), Vol. 3, No.3, Pp. 337 - 343.

[14] Hamid R.E, Omid D and Mohsen M. (2014): "Optimal placement and sizing of DG units and capacitors simultaneously in radial distribution networks based on the voltage stability security margin" Turkish Journal of Electrical Engineering and Computer Sciences, http:// journals. tubitak.gov.tr/elektrik/, Vol. 9, No. 3, Pp. $1-14$.

[15] Haruna M and Sanusi S.A. (2013): “Optimal allocation and sizing of distributed generation for power loss reduction using modified PSO for radial distribution systems" Journal of Energy Technologies and Policy, Vol.3, No.3, Pp. 1 - 9.

[16] Hossein N and Morteza N. (2012): "Load model effect assessment on optimal distributed generation sizing and allocation using improved harmony search algorithm" Research Journal of Applied Sciences, Engineering and Technology, Vol.2, No. 7, Pp. 832- 837.

[17] Ibrahim T.A. (2009): "Optimal sizing of capacitor banks and distributed generation in distorted distribution networks by genetic algorithms" International Conference on Electricity Distribution, Vol. 4, No. 4, Pp. 811.

[18] Jasrul J.J and Mohd W.M. (2012): "Distributed generator sizing: an iteration particle swarm optimization approach” IASTED International Conference Power and Energy System, Vol. 5, No. 9, Pp. 439 - 444.

[19] Jegadeesan M and Keerthana V. (2014): "Optimal sizing and placement of distributed generation in radial distribution feeder using analytical approach" International Journal of Innovative Research in Science, Engineering and Technology,Vol. 3, No. 3, Pp. 358 - 364.

[20] Julius K.Cand Nicodemus A.O. (2013): "Effect of distributed generation penetration on system power loss and voltage profile" International Journal of Scientific and Research Publications, Vol. 3, No. 5, Pp. 22503153.

[21] Kansal, S., Sai, B. B. R., Tyagi, B. and Kumar, V. (2011). Optimal placement of distributed generation in distribution networks. International Journal of Engineering, Science and Technology, 3(3): 47-55.

[22] Kavitha D and Muthamil S.P. (2014): "Optimal sizing and placement of distributed generators in distorted distribution system by using hybrid GA- PSO" Journal of Theoretical and Applied Information Technology, Vol. 61 No.3, Pp. $609-616$.

[23] Lieven D, Renders B, Meersman B and Lieven V. (2012): "Influence of converter-connected distributed generation on distribution network losses" Textbook on Electrical Power Generation, http://www.icidr.org.Pp. Vol. 2, No. 6, Pp.1-10.।

[24] Manafi H, Ghadimi N, Ojaroudi M and Farhadi P. (2013): "Optimal placement of distributed generations in radial distribution systems using various PSO and DE algorithms" ElektronikaI Elektrotechnika, Vol. 19, No. 10 , Pp. $53-57$.

[25] Manjunatha S and Vittal K.P. (2010): “A heuristic approach to distributed generation source allocation for electrical power distribution systems" Iranian Journal of Electrical and Electronic Engineering, Vol. 6, No. 4, Pp. 224 -232.

[26] Mehdi H and Reza B. (2013): “Optimal placement of DGs in distribution system including different load models for loss reduction using genetic algorithm" Journal of Advance in Computer Research, Vol. 4, No. 3, Pp. 55-68.

[27] Meysam K, Ahad K and Mohammad S.Z.S (2009): "Optimization of distributed generation placement for minimizing power losses and voltage profile improvement using genetic algorithm" International Journal of Advanced Computer Science, Vol. 2, No. 10, Pp. 376-381.

[28] Mohamed S and Petinrin J.O. (2013): "Sizing and sitting of distributed generation in distribution systems for voltage improvement and loss reduction" International Journal of Smart Grid and Clean Energy, Vol. 2, No. 3, Рp. $351-356$.

[29] Mohammad M and Akbari M.N. (2011): "PSO based multi objective approach for optimal sizing and placement of distributed generation" Alexandria Engineering Journal, Vol. 52, No.3, Pp. 655-663.

[30] Mohammad V and Seyyed M.H. (2010): "Determination of optimum size and location of distributed 
generators for loss reduction using GA” Journal of Electrical Engineering, www.jee.ro. Vol. 15, No.10, Pp. $24-40$.

[31] Mohit M, Rajat K and Shivani S. (2012): "Analytical approaches for optimal placement and sizing of distributed generation in power system" Journal of Electrical and Electronics Engineering, Vol. 1, No. 6, Pp 20-30.

[32] Nasser Y and Gholamreza A. (2014): “A Comparison of various algorithms in optimal sizing and sitting of distributed generation in power system” MAGNT Research Report, Vol. 2, No. 7, No. 4, Pp. 951-957.

[33] Nurul Iman Y. (2009): "Placement impact of distributed generation in distribution networks" http://google.com/. Vol. 18, No.7, Pp. 1- 24.

[34] Ramakanth S and Vinod D.M.K. (2014): “Optimal sizing and location of distributed generation using improved teaching-learning based optimization algorithm” International Journal of Advanced Technology \& Engineering Research (IJATER), Vol. 8, No. 6, Pp. 116-123.।

[35] Rashmi P and Surya P. (2014): "Optimal location and sizing of generator in distributed generation system" International Journal of Innovative Research in Electrical, Electronics, Instrumentation and Control Engineering, Vol. 2, No. 5, Pp. $1272-1278$.

[36] Satish K, Sai B.B.R, Barjeev T and Vishal K. (2011): "Optimal placement of distributed generation in distribution networks" International Journal of Engineering, Science and Technology, Vol.3, No.3, Pp. 4755.

[37] Sedighizadeh M and Rezazadeh A. (2008): "Using genetic algorithm for distributed generation allocation to reduce losses and improve voltage profile" World Academy of Science, Engineering and Technology, Vol. 37, No. 1, Pp. $251-257$.

[38] Slaven K, Damir S and Saša M. (2012): "The optimal placement of distributed generation" http://www.iiste.org. Vol. 4, No. 2, Pp. $56-70$.

[39] Srinivasa K.R and Nageswara M.R. (2012): “Optimal placement of multiple distributed generator by HS algorithm" International Journal of Engineering Research and Applications, Vol. 2, No. 5, Pp.1290-1294.

[40] Subrahmanyam J.B.V and Radhakrishna C. (2009): "Distributed generator placement and sizing in unbalanced radial distribution system” International Journal of Electrical and Electronics Engineering Vol. 3, No.12, Pp.746 - 752.I

[41] Syed S.H and Shah J. (2012): "Impact of distributed generation on distribution systems and its protection" www.netjournals.org. Vol.1, No. 3, Pp. $1-14$.

[42] Vivek K.S, Rahi O.P and Vaibhav T. (2012); "Optimal placement methods of distributed generation: A review" Proc. of the Intl. Conf. on Advances in Computer, Electronics and Electrical Engineering, Vol. 5, No. 8, Pp. $466-476$. 